\section{VALORACIÓN Y CONFIANZA DE LOS ESPECTADORES DE LOS PROGRAMAS DE SALUD DE TVE}

\author{
Lorena Cano-Orón \\ Universidad de Valencia \\ https://orcid.org/0000-0003-4270-1924 \\ Lorena.Cano@uv.es \\ Marta Portalés Oliva \\ Universitat Autònoma de Barcelona \\ https://orcid.org/0000-0002-9143-3551 \\ marta.portales@e-campus.uab.cat
}

Cómo citar este artículo/Citation: Cano-Orón, L. y Portalés Oliva, M. (2019). Valoración y confianza de los espectadores de los programas de salud de TVE. Arbor, 195 (793): a520. https:// doi.org/10.3989/arbor.2019.793n3008

Recibido: 7 julio 2017. Aceptado: 10 febrero 2019.

RESUMEN: Televisión Española (TVE) ha hecho posible la divulgación de temas médicos en la temporada de 2016 a través de los cuatro programas especializados en salud: Saber vivir, Centro médico, Esto es vida y El ojo clínico. Con el objetivo de conocer mejor su recepción por parte de los telespectadores, este estudio analiza, por un lado, los datos oficiales de audimetría y, por otro, los de una encuesta lanzada a través de las redes sociales. Con el cuestionario, al que han respondido 158 seguidores de los programas, se ha medido la valoración y la confianza que los espectadores otorgan al tratamiento informativo y audiovisual de estos programas. Esta investigación se corresponde con la segunda fase de un proyecto más amplio en el que previamente se han estudiado los contenidos de los programas televisivos y su comunicación digital a través de Twitter.

PALABRAS CLAVE: elevisión; salud; recepción; audiencia; TVE; alfabetización en salud.

\section{VALUATION AND CONFIDENCE OF THE HEALTH PROGRAMS OF TVE SPECTATORS}

Copyright: (C) 2019 CSIC. Este es un artículo de acceso abierto distribuido bajo los términos de la licencia de uso y distribución Creative Commons Reconocimiento 4.0 Internacional (CC BY 4.0).

ABSTRACT: Televisión Española (TVE) has made possible the dissemination of medical topics in the 2016 season through four specialized health programs: Saber vivir, Centro médico, Esto es vida and El ojo clínico. In order to better understand their reception by spectators, this study analyzes, on the one hand, the data from the audiometry and, on the other hand, the results of a survey launched through social networks. The questionnaire, responded by 158 followers of the programs, measured the value of the programs and the spectators' confidence in their informative and audiovisual treatment. This research corresponds to the second phase of a broader project in which the contents of television programs and their digital communication through Twitter have been previously studied.

KEYWORDS: Television; health; reception; audience; TVE; health literacy. 


\section{INTRODUCCIÓN}

Según los datos ofrecidos por el Centro de Investigaciones Sociológicas (CIS), la sanidad es un asunto importante para los ciudadanos españoles. En el último barómetro sanitario realizado hasta la fecha (Barómetro sanitario 2015 (tercera oleada)) la sanidad se posiciona como el segundo ítem de mayor interés, por detrás del trabajo, para la ciudadanía española. Asimismo, según el barómetro de 2016 (Barómetro de noviembre 2016. Avance de resultados), entre los temas presentados en noticias, la materia relativa a los avances médicos es la que más interés suscita. No obstante, "la relevancia noticiosa de la sanidad [en los telediarios] es secundaria tanto en la cadena estatal como en las privadas" (Francescutti, 2012, p. 37).

La televisión sigue siendo el medio al que más expuestos están los ciudadanos para informarse sobre ciencia y tecnología (Torres Albero, 2015), sobre todo en edades superiores a los 45 años (Lobera, 2017), aunque no sean abundantes estos contenidos (Moreno Castro, 2009) y suelan estar programados en horarios que dificultan conseguir máxima audiencia (Lehmkuhl, 2014; León, 2002; Moreno Castro, 2004). En concreto, en cuanto a contenidos sobre medicina y salud, la oferta televisiva no se corresponde con la demanda potencial del público (Semir y Revuelta, 2006). En esta línea es la televisión pública la que por ley está obligada a "promover el conocimiento de las artes, la ciencia, la historia y la cultura" (ley 17/2006, art. 3) y a servir de ventana al conocimiento. TVE programa contenidos de divulgación de la ciencia en diversas franjas horarias que ayudan a alcanzar tal objetivo, pero ¿cómo recibe la audiencia estos contenidos?

Este trabajo realiza un análisis exploratorio que permite, por un lado, conocer esencialmente las características de la recepción de los programas de salud de TVE emitidos en 2016. Por otro, conocer el tipo de audiencia que consume este tipo de contenidos, a partir de los datos oficiales de audiencia y de las respuestas de los 158 cuestionarios de espectadores de estos programas.

Las preguntas que guían este estudio son: a) ¿qué rasgos sociodemográficos tiene la audiencia?, para conocer quiénes son los espectadores asiduos y comprender así la concordancia o no con el estilo audiovisual del programa, y b) ¿cómo percibe y valora la audiencia el tratamiento informativo y audiovisual que caracteriza a estos programas? (Cano-Orón, Portalés Oliva y Llorca-Abad, 2017).

\subsection{Programas de salud en TVE}

Los inicios del periodismo especializado en salud en TVE se sitúan en la década de los 70. En concreto, comienza con Escuela de salud ${ }^{1}$, el primer programa de salud de la historia de la televisión española (Terrón Blanco, 2007), dirigido por Manuel Torreiglesias, definido por los boletines de TVE como "programa motivador de comportamiento sanitario" (véase Finaliza el programa de TVE "Escuela de salud") y seguido por otro gran referente en la historia de TVE, Más vale prevenir (http://www. rtve.es/alacarta/videos/mas-vale-prevenir/), que estuvo en antena desde 1979 a 1987, con Ramón Sánchez Ocaña como presentador, quien se posiciona como especialista en esta área temática (Terrón Blanco, 2007). En 1988 volvería con Diccionario de la salud (TVE), un programa que seguía la trayectoria de Más vale prevenir (TVE), y en 1991 con Los hijos del frío (TVE), un programa especializado en la investigación médica.

Formatos como el de Más vale prevenir marcaron la forma de abordar la salud en televisión en España, pues es una fórmula que se repite constantemente: "espacios que tratan de manera coloquial y genérica la prevención y promoción de la salud, con la inclusión de explicaciones y posibles tratamientos de patologías comunes [...] con objeto de resolver dudas y ofrecer información a los espectadores" (López Villafranca, 2015, p. 161).

En la década de los 90 destaca el programa de salud Saber vivir, presentado en su primera temporada por Manuel Torreiglesias y Teresa Viejo². El programa, que reproduce la esencia de Más vale prevenir (Moreno Castro, 2004, p. 130), estuvo en antena desde 1997 a 2009, a partir de entonces pasaría a integrarse como una sección dentro del magacín matinal La mañana. En 2017 el programa volvería a independizarse siguiendo el formato matinal tradicional, pero solo duraría un año. En febrero de 2019, volvería a estar en antena, de forma independiente, ocupando un espacio semanal en la segunda cadena.

Para cumplir con la misión de servicio público, Saber vivir afirma basarse en cuatro recursos: 1) enseñar las pautas elementales de vida, 2) dar a conocer a los especialistas más expertos, con mayor autoridad científica y técnica en las distintas ramas de las ciencias de la salud, 3) facilitar la participación directa de la audiencia, y 4) promocionar el servicio social prestado por los distintos colectivos sociales (véase Saber vivir. 2000 días a tu lado, p. 12). 
No obstante, en la práctica y a lo largo del tiempo, han sido varias las quejas recibidas por diversos contenidos del programa. En primer lugar, destaca la publicidad hacia derivados del programa y otros servicios y productos. TVE despidió a su presentador original, Manuel Torreiglesias, por irregularidades en la publicidad (Gallo, 2009, 8 mayo) y a Comisión Nacional de los Mercados y la Competencia (CNMC) condenó a la cadena a pagar una multa por las prácticas de publicidad encubierta detectadas en la sección de La mañana (Pérez Mendoza, 2016, 11 octubre). En segundo lugar, otro elemento que se ha criticado de forma insistente en los últimos años es la falta de rigor científico y la promoción de terapias y soluciones no convencionales, como el fomento de la homeopatía (Gámez, 2015, 3 enero; Martínez, 2015, 3 enero). En esta línea, y debido a la afirmación de la presentadora, Mariló Montero, sobre las propiedades curativas del cáncer que tiene el aroma de limón, TVE se vio obligada a emitir un comunicado como reacción a las múltiples quejas recibidas, entre ellas de la Organización Médica Colegial (véase Carta al Defensor del Espectador de TVE: La OMC envía una queja por las declaraciones de Mariló Montero). El comunicado afirmaba: "Saber vivir no puede ni debe aconsejar la práctica de la aromaterapia como vía para la prevención del cáncer, ni de cualquier otra técnica o terapia que no esté avalada por las organizaciones médicas del ámbito de la oncología en nuestro país" (véase Comunicado del espacio de TVE 'Saber vivir'). Tal ha sido la repercusión de este discurso que a raíz de los comentarios de Mariló Montero se presentó una proposición no de ley en el Congreso de los Diputados para que RTVE cumpliese con la normativa vigente en las informaciones referidas a salud (Sevillano, 2015, 23 abril).

En el periodo estudiado, la temporada de 2016, los programas específicos que tratan la salud en TVE son los siguientes (Cano-Orón et al., 2017):

La sección Saber vivir dentro del matinal La mañana (http://www.rtve.es/television/la-manana-dela-1/saber-vivir/): la sección del matinal previamente comentada.

Centro médico (http://www.rtve.es/television/ centro-medico/): una docuficción, de periodicidad diaria, en la que se presentan casos clínicos reales presentados como casos de ficción, basada en un formato de éxito internacional. Presenta pequeñas explicaciones al espectador, rompiendo la cuarta pared -es decir, dirigiéndose directamente al especta- dor-, para aclarar terminología, síntomas y procesos que aparecen durante el programa.

Esto es vida (http://www.rtve.es/television/estoes-vida/): infotainment diario presentado por Cristina Lasvignes y tres médicos, Fernando Uribarri (pediatra), Luis Benito (digestivo) y Paloma Borregón (dermatóloga). Con público y testimonios en directo, se desarrollan secciones lúdicas, animadas y divulgativas.

El ojo clínico (http://www.rtve.es/television/ el-ojo-clinico/): programa semanal de divulgación médica de carácter más formal que los anteriores, sin público en directo. Está presentado por Ana Gugel, periodista, y Cristina Torres, neurocirujana. Cada programa es monográfico y se aborda desde diversas perspectivas que corresponden con sus distintas secciones, como son la historia, los datos actuales sobre el tema, los testimonios de afectados y expertos. El programa cierra con un debate final con expertos.

En concreto han coincido en parrilla solo tres de ellos, pues Esto es vida acabó su emisión antes de que comenzase El ojo clínico. Mientras se emitía Esto es vida en La 1, la cadena emitía tres programas diarios sobre salud (la sección de Saber vivir, Centro médico y Esto es vida). Este dato fue destacado por la prensa por el cambio de programación que suponía respecto a la tradición vespertina de $L a 1$, que daba protagonismo a la salud (Álvarez, 2015, 26 octubre; La nueva apuesta de salud para las tardes de TVE provoca un intenso debate entre los directivos; Salud y bienestar en las tardes de TVE).

\subsection{Alfabetización en salud como efecto del consumo televisivo}

Sharf y Freimuth (1993) entienden que la televisión, y en concreto los programas de entretenimiento y ficción, crean para la ciudadanía una construcción ideológica concreta de la enfermedad. Son una fuente de información que la alerta ante posibles síntomas y posibles consecuencias, que construye el imaginario sobre qué esperar cuando alguien es diagnosticado con una enfermedad concreta.

Este tipo de contenidos orientan a la población para tomar decisiones y prepararse. Por ejemplo, una anécdota que destaca Sánchez Martos (2010) para demostrar el efecto que los medios de comunicación tienen en los hábitos de la población es que España aumentó el número de mujeres interesadas en hacerse mamografías justo cuando una 
de las protagonistas de la telenovela Cristal, cuya emisión en 1990 en España supuso un fenómeno social, sufría un cáncer de mama.

Los programas especializados en salud cuya narrativa presenta la experiencia de la enfermedad y desarrolla las implicaciones que conlleva vivir con ella ofrecen lo que se define como patografía (Sharf y Freimuth, 1993). Estos programas se sustentan a partir de información obtenida en primera persona por pacientes que han sufrido tales dolencias o familiares cercanos que pueden aportar información precisa sobre el estado y el desarrollo de la enfermedad.

Los estudios de alfabetización en salud se dividen actualmente en dos paradigmas (Aldoory, 2017). Por un lado, la visión centrada en las cualidades de los sujetos y en el nivel de educación en salud que poseen, y por tanto en la adaptación de las intervenciones de alfabetización a sus perfiles y necesidades. Y, por otro lado, el enfoque universal de precauciones (universal precautions approach), que unifica al público asumiendo una baja alfabetización, y como consecuencia emite mensajes claros, adecuados a ese nivel y sensibles culturalmente. En este segundo paradigma sería en el que se moverían los programas de televisión de TVE, creados para una amplia horquilla de audiencia con una educación básica.

Los objetivos principales de los programas de educación y entretenimiento especializados en salud son: a) aumentar el conocimiento de la audiencia, y b) ser capaces de transmitir contenidos que fomenten actitudes favorables hacia temas de salud y comportamientos que permitan crear hábitos saludables. No obstante, como apuntan MoyerGusé y Nabi (2011), la persuasión potencial que pueden producir los mensajes emitidos en estos programas depende de las características particulares de cada espectador. Su estudio deja la puerta abierta a la posibilidad de que los mensajes puedan ser tan efectivos como dañinos en función de cómo sean interpretados por la audiencia. A pesar de que la audiencia tenga capacidades para mantenerse informada sobre temas de salud, cabe también detectar en qué medida es capaz de discernir entre información verdadera o falsa, así como descodificar la narrativa audiovisual, específicamente en los tipos de programas que son objeto de estudio de esta investigación. En esta línea es preciso comentar el trabajo realizado por Lazo y Grandío (2013) desde la perspectiva de los estudios de recepción, que trata específicamente sobre las competencias críticas e informativas de la población española, pues la alfabetización mediática en estos casos es clave para poder distinguir la calidad de la información y las habilidades de descodificación de mensajes. Estas autoras concluyen que "el perfil del ciudadano en la dimensión de recepción y audiencias es el de alguien que desconoce cualquier mecanismo de defensa ante los mensajes impropios que se emiten en los medios audiovisuales, al tiempo que ignora el marco jurídico que le protege y ampara como receptor" (Lazo y Grandío, 2013, p. 127). Destacan la "incapacidad de descodificación emocional por parte de la audiencia española" y la "falta de empoderamiento en la audiencia española". EI estudio de Lazo y Grandío (2013) destaca porque desmarca a la población española respecto a otros resultados internacionales (Asbeek Brusse, Fransen y Smit (2015), pues concluye que los espectadores españoles entienden que es inmoral el uso de estrategias persuasivas en este tipo de programas para patrocinar ciertas marcas, como se ha visto anteriormente en la denuncia de la CNMC.

En esta línea, Yoo y Tian (2011) advierten de la posible desconfianza en la medicina y en el trabajo de los profesionales sanitarios que se puede generar en la audiencia cuando se difunden mitos en este tipo de programas. No obstante, también señalan que son aquellas personas sin experiencias o conocimientos previos sobre el tema las que son más susceptibles de ser influidas por este tipo de discursos.

Como señalan Peñafiel, Ronco y Echegaray (2016) y Echegaray Eizaguirre, Peñafiel Saiz y Aiestaran Yarza (2014), estamos ante una época en la que la información sanitaria ha aumentado y se ha facilitado el acceso a ella. Y cada vez más los ciudadanos tienden a buscar respuesta a sus inquietudes a través de los medios y de internet:

"El aumento de información sobre salud en los medios de comunicación ha tenido una influencia definitiva en lo que podríamos llamar la creación de un nuevo paciente. Un efecto que incide en el comportamiento del denominado 'paciente activo'" (Echegaray Eizaguirre et al., 2014, p. 251).

Estamos ante un paciente informado, que ha estado expuesto tanto a noticias como a información y testimonios de pacientes.

"Como resultado del incremento y proliferación de noticias de salud los profesionales observan la apa- 
rición de un nuevo tipo de paciente, más leído, más informado, más conocedor. También más influido. Es lo que se ha denominado el "paciente informado" (Echegaray Eizaguirre et al., 2014, p. 254).

Según Domínguez Lázaro (2015), los elementos clave para una buena comunicación de la salud en formato audiovisual son: razón, emoción y conducta del público. El autor afirma que para que un programa de televisión cause un efecto en el público, "debe tener ciertas dosis de elementos cognitivos que apelen a la razón de los telespectadores, así como elementos emotivos que vayan directos a las emociones y los sentimientos del receptor, sin olvidar la necesidad de incluir mensajes directamente conductuales que indiquen claramente cuál es el objetivo perseguido y como se espera que quien recibe el mensaje reaccione" (Domínguez Lázaro, 2015, p. 60).

Es necesario apuntar que, como sugieren Quintero Johnson, Harrison y Quick (2013), la información sobre salud insertada en una narrativa ayuda a recordarla, pero también se ha comprobado que las historias que atraen en gran medida al espectador distraen la atención de la información que están difundiendo. Es necesario crear un producto que esté en equilibrio entre una buena narrativa y un énfasis en la información que se quiere transmitir.

\section{MATERIAL Y MÉTODOS}

Esta investigación exploratoria forma parte de un estudio empírico más amplio desarrollado en dos fases en el que se analizan los programas de televisión especializados en salud emitidos por TVE durante 2016. La primera fase de la investigación se centró en el análisis de contenido de los programas, identificando el tratamiento informativo y audiovisual, y su comunicación digital en Twitter (Cano-Orón et al., 2017). En la segunda fase, que aquí se presenta, el objeto de estudio es la audiencia; concretamente, su interpretación y recepción de estos contenidos.

Para realizar este estudio de recepción se realiza, por un lado, un análisis de los datos oficiales de audiencia de los programas de salud emitidos en 2016 en TVE -Saber vivir, Centro Médico, Esto es vida y El ojo clínico- y por otro lado, un cuestionario que recoja la valoración de la audiencia de estos programas. En cuanto a los datos oficiales, se accedió a los registrados en la temporada de 2016 a través de la consultora audiovisual Género, Estética y Cultura Audiovisual (GECA) (http:// www.geca.es/), para poder tener más información cuantitativa sobre la audiencia aproximada de cada programa, accediendo a datos sobre el share pero también sobre la edad y el sexo de la audiencia media de la cadena y del programa. De este modo comparamos el tipo de público que tiene el programa respecto a la cadena y complementamos la información de las encuestas.

El diseño del cuestionario se realizó teniendo en cuenta las variables analizadas en el análisis de contenido de los programas de TVE en la fase anterior (Cano-Orón et al., 2017). Cuenta con once preguntas: tres sociodemográficas, una de selección del programa más visto y siete específicas para medir la recepción de los programas (véase la tabla 1). El cuestionario se realizó con typeform.com y se difundió en línea durante el mes de diciembre de 2016. La invitación a participar se extendió a espectadores de estos programas y a usuarios que habían interactuado en las cuentas oficiales de los programas en Twitter y Facebook.

El corpus del que parte esta investigación está compuesto por los datos recogidos en un cuestionario cumplimentado por 158 personas, realizado al público de los programas de televisión en salud de TVE emitidos en 2016: Saber vivir (106 respuestas), Centro médico (35 respuestas), Esto es vida (5 respuestas) y El ojo clínico (12 respuestas), que interactúa y deja comentarios en las redes sociales.

El porcentaje de respuestas obtenidas por programa coincide parcialmente con los datos de share de los programas (véase la tabla 2). Un $67 \%$ son espectadores de Saber vivir, seguramente el más conocido por llevar en antena desde 1997, seguido por el popular Centro médico, con un $22 \%$ de las respuestas y de Esto es vida, con tan solo un $3 \%$. Este hecho puede ser debido a que el programa se emitió únicamente durante cuatro meses. El porcentaje de respuesta sobre El ojo clínico también es pequeño, un $8 \%$, posiblemente debido a su periodicidad semanal y al poco tiempo que llevaba en antena, pues sus emisiones se iniciaron en febrero 2016.

Con objeto de que la investigación sea lo más rigurosa posible, no se han modificado los textos de las respuestas a las preguntas abiertas que escribieron los espectadores en el formulario. Es decir, se dejaron los errores gramaticales, de sintaxis y de cualquier orden. Se ha utilizado para la investigación una serie de textos seleccionados para ejemplificar que no han sido sometidos a ningún rigor académico, tal y como veremos en los resultados. 
Tabla 1. Diseño del cuestionario utilizado

\begin{tabular}{|l|l|}
\hline \multicolumn{2}{|l|}{ Preguntas sociodemográficas } \\
\hline 1. Sexo & a. Hombre b. Mujer \\
\hline 2. Edad & Número de años \\
\hline 3. Estudios & $\begin{array}{l}\text { a. Estudios básicos } \\
\text { b. Estudios medios (Bachillerato / Ciclo Formativo) } \\
\text { c. Estudios superiores (Universidad) } \\
\text { d. Otra / Ninguna }\end{array}$ \\
\hline
\end{tabular}

Selección del programa

[condiciona el resto de preguntas. En el formulario cada vez que aparece programa aparecía el nombre seleccionado en esta pregunta]

\begin{tabular}{|l|l}
\hline$¿ Q u e ́$ programa has visto? & $\begin{array}{l}\text { a. Saber vivir } \\
\text { b. Centro médico } \\
\text { c. El ojo clínico } \\
\text { d. Esto es vida }\end{array}$ \\
\hline
\end{tabular}

Preguntas específicas sobre el programa

5. ¿Cuánto confías en la información $\quad$ (Escala Likert) que aporta?

6. ¿Con cuál de las siguientes

a. Entiendo los conceptos científicos, porque los explican.

afirmaciones te sientes identificado?

b. Usan términos científicos que no explican y yo, personalmente, no los entiendo, pero claramente saben de lo que hablan y son verdad.

c. Ninguna de las anteriores.

7. Evalúa la calidad de la información sobre salud en el programa.

Los expertos

[médicos, científicos]

(Escala Likert)

Los testimonios del público

[Por ejemplo: las llamadas, el público en el plató, los pacientes en Centro médico y la gente de la calle en El ojo clínico]

(Escala Likert)

La información del programa en general

[Por ejemplo: las Ilamadas, el público en el plató, los pacientes en Centro médico y la gente de la calle en El ojo clínico]

(Escala Likert)

8. ¿Qué consideras que te ayuda a entender mejor la ciencia del programa?

a. Anotaciones [pizarra electrónica]

b. Dibujos animados [funcionamiento de los órganos del cuerpo]

c. El ritmo se adapta a la explicación

d. Teatralización del presentador [explicaciones exageradas o dramatizadas]

e. Videos externos grabados fuera del plató [reportaje en un hospital, un testimonio, etc.]

\section{\begin{tabular}{l|l} 
9. ¿Qué otras cosas te ayudan a & Respuesta abierta
\end{tabular}}

entender mejor la ciencia?

10. ¿Por qué ves el programa? ¿Qué te aporta? ¿Aprendes?

11. ¿Quieres comentarnos algo más?

Respuesta abierta

Respuesta abierta

Fuente: Elaboración propia. 
Tabla 2. Audiencia de los programas de salud

\begin{tabular}{|l|c|c|c|}
\hline \multicolumn{3}{|c|}{ Audiencia de la temporada } \\
\hline & Miles & Rating & Share \\
\hline Centro médico & 614 & 1,4 & 6,5 \\
\hline Saber vivir & 230 & 0,5 & 7,9 \\
\hline Esto es vida & 524 & 1,2 & 4,9 \\
\hline El ojo clínico & 95 & 0,2 & 1,4 \\
\hline
\end{tabular}

Fuente: Elaboración propia a partir de los datos de GECA.

\section{RESULTADOS}

Para analizar los niveles de audiencia, conseguidos a partir de los datos de GECA (véase tabla 2), es importante destacar las cifras de share o 'cuota de pantalla', pues esta medida tiene como referencia los televisores encendidos en el territorio español y los programas analizados no se superponen en franja horaria. Para poder comparar la audiencia de los programas atenderemos a las cifras de rating o 'índice de audiencia', un dato que hace referencia al universo total de televisores, encendidos y apagados, en la muestra analizada (véase Rating es 'índice de audiencia' y share, 'cuota de pantalla').

En esta línea, Centro médico destaca por el rating más alto $(1,4)$, es decir, es el que más espectadores tiene respecto al número de audiencia total muestreada, por lo que podríamos afirmar que es el que más audiencia tiene de media de los cuatro programas. No obstante, es necesario destacar que Saber vivir se sitúa como el programa que más audiencia tiene en cuanto a share $(7,9)$. Es decir, este programa es el programa de TVE de salud más visto, atendiendo a la referencia de los televisores encendidos en el momento de emisión.

La audiencia media de los programas tiende a un perfil mayoritariamente femenino, aunque la diferencia entre sexos no es muy pronunciada. Como se puede observar en la tabla 3 , los programas suelen exceder la cuota media de audiencia femenina de la cadena. En este aspecto destaca El ojo clínico por tener una cuota mucho más repartida, con un $46 \%$ de hombres y un $54 \%$ de mujeres, y Centro médico por ser el que más público femenino atrae, según los datos de GECA. La muestra del cuestionario está compuesta principalmente por mujeres: $59 \%$ frente a un $41 \%$ de hombres, y sigue la tendencia de la audiencia presentada por GECA (véase la tabla 3 ).

La media de edad de los encuestados de Saber vivir es de 43 años, la de Esto es vida de 40 años, la de El ojo clínico de 38 años y la de Centro médico de 36 años. Las edades difieren con los datos de GECA (véase la tabla 4), pues estos señalan que el mayor porcentaje de la audiencia de estos programas tiene más de 45 años, siendo el segmento con más audiencia los mayores de 64 (dato sombreado en verde en la tabla 4). De este modo, aunque sin un gran margen de diferencia, Saber vivir se posiciona como el programa con más audiencia de mayores de 64 años de los cuatro. Este dato también se justifica por la franja horaria en la que se emite: horario matinal coincidente con el horario laboral.

La diferencia de media de edad que presentan los datos de GECA respecto a los obtenidos a través del cuestionario puede deberse al tipo de vía elegida para la participación en el estudio: las redes sociales, que cuentan con una media de edad más joven que la de la audiencia de los programas analizados.

Tabla 3. Perfil de la audiencia en función del sexo

\begin{tabular}{|l|c|c|c|c|c|c|c|c|}
\cline { 2 - 10 } \multicolumn{1}{c|}{} & \multicolumn{2}{c|}{ Centro médico } & \multicolumn{2}{c|}{ Saber vivir } & \multicolumn{2}{c|}{ Esto es vida } & \multicolumn{2}{c|}{ El ojo clínico } \\
\cline { 2 - 10 } & Hombres & Mujeres & Hombres & Mujeres & Hombres & Mujeres & Hombres & Mujeres \\
\hline Perfil cadena & 42 & 58 & 40,3 & 59,7 & 43,5 & 56,5 & 48,8 & 51,2 \\
\hline Perfil programa & 35,1 & 64,9 & 36,9 & 63,1 & 38,4 & 61,6 & 45,9 & 54,1 \\
\hline
\end{tabular}

Fuente: Elaboración propia a partir de los datos de GECA. 
En cuanto a las valoraciones de los espectadores de los aspectos de los programas analizados, destaca en primer lugar el nivel de confianza en la información que ofrecen los contenidos televisivos. Los espectadores encuestados confían en la información del programa con una media de 2.92 sobre 5 (donde 1 es "no confío nada en la información" y 5 "confío mucho en la información"). Este dato coincide cuando los encuestados evalúan la calidad de la información del programa, que también se sitúa en 2,84 sobre 5 (donde 1 es "la calidad de la información proporcionada es muy mala" y 5 "la calidad de la información proporcionada es muy buena").

Sin embargo, la evaluación por parte de los encuestados de la calidad de la información proporcionada por los médicos y expertos científicos invitados al programa se sitúa por encima de esta media del programa con un 3,31 sobre 5 . En cambio, según los encuestados, la calidad de la información proporcionada por los testimonios del público se halla más de un punto por debajo de la media general del programa: en 2,61 sobre 5 .

Si comparamos estos datos desglosados en función del programa televisivo, destaca la confianza depositada en los contenidos de El ojo clínico. Los valores sobre la calidad de la información -tanto la aportada por los expertos como la procedente de los testimonios- y sobre la confianza que esta suscita en la audiencia se sitúan un punto por encima de los respectivos valores de Saber vivir. En el gráfico 1 se puede observar la diferencia.

En los siguientes gráficos podemos observar estos mismos datos a partir de los segmentos de edad que proporcionan los datos de GECA. Para simplificar el gráfico 2, se puede observar la siguiente media o tendencia, pero se ha de tener en cuenta el número de respuestas por grupo de edad: 14-24 $(n=17), 25-44(n=70), 45-64(n=67)$ y $>64(n=4)$. Sin embargo, este gráfico nos muestra que las generaciones entre los 25-44 años, entre las que destacan los millenials, son las que menos confían en la información, mientras que los inmigrantes digitales, así denominados por Prensky, son menos críticos y confían más en la información.

Estos gráficos deben leerse entendiendo la distribución de la edad y el coeficiente de Pearson. Los encuestados están principalmente concentrados en su mayoría entre las edades comprendidas entre los 32 y los 52 años, y la muestra tiene principalmente una media de edad de 42,5 años (véase gráfico 4).

Las variables son dependientes, tienen una relación pequeña, el coeficiente de Pearson ( $r$ ) es de 0,15 y la determinación es del $2 \%$ para la correlación entre la edad y la confianza en la información aportada por los expertos, y en el caso de la correlación entre edad y confianza en la información de los testimonios, la correlación es dos puntos mayor, con una determinación del $4 \%$ y un coeficiente de Pearson ( $r$ ) de 0,2. Por lo tanto, en ambos casos la correlación lineal es muy débil pero indica una tendencia.

En cuanto a las explicaciones de los conceptos científicos que se dan en los programas (véase gráfico 5), un $55 \%$ de los espectadores encuestados las valora positivamente. Sin embargo, un $6 \%$ afirman no entender los términos, pero confiar plenamente en la información recibida sin cuestionarla. Por lo tanto, existe un porcentaje pequeño, pero significativo, de espectadores no críticos con la información que reciben. Cabe destacar que un $39 \%$ no se posiciona en ninguna de estas dos posturas y, por lo tanto, no se siente identificado con el extremo de confiar totalmente en la información ni tampoco considera que el programa le aporte conocimientos científicos.

Tabla 4. Segmentación de la audiencia en porcentaje en función de la edad

\begin{tabular}{|c|c|c|c|c|c|c|c|c|c|c|c|c|c|c|c|c|c|c|c|c|}
\hline \multirow[b]{2}{*}{$\begin{array}{l}\text { Intervalos de } \\
\text { edad }\end{array}$} & \multicolumn{5}{|c|}{ Centro médico } & \multicolumn{5}{|c|}{ Saber vivir } & \multicolumn{5}{|c|}{ Esto es vida } & \multicolumn{5}{|c|}{ El ojo clínico } \\
\hline & $4-12$ & $13-24$ & $25-44$ & $45-64$ & $>64$ & $4-12$ & $\mid 13-24$ & $25-44$ & $45-64$ & $>64$ & $4-12$ & $\mid 13-24$ & $25-44$ & $45-64$ & $>64$ & $4-12$ & $\mid 13-24$ & $25-44$ & $45-64$ & $>64$ \\
\hline $\begin{array}{l}\text { Perfil de la } \\
\text { cadena }\end{array}$ & 4,7 & 5,3 & 18,8 & 33,8 & 37,4 & 3,4 & 4,8 & 23,3 & 32,4 & 36 & 5,7 & 5,3 & 19,9 & 32,4 & 36,7 & 7,5 & 6,2 & 23,1 & 33,8 & 29,4 \\
\hline $\begin{array}{l}\text { Perfil del } \\
\text { programa }\end{array}$ & 2,8 & 3,3 & 10,1 & 34,2 & 49,6 & 0,4 & 1,2 & 11,5 & 31 & 55,9 & 2 & 2,7 & 11,1 & 38,6 & 45,5 & 1,2 & 1,3 & 9,4 & 35,8 & 52,3 \\
\hline
\end{tabular}

Fuente: Elaboración propia a partir de los datos de GECA. 
Gráfico 1. Niveles de calidad de la información y confianza en el programa ( $n=158)$

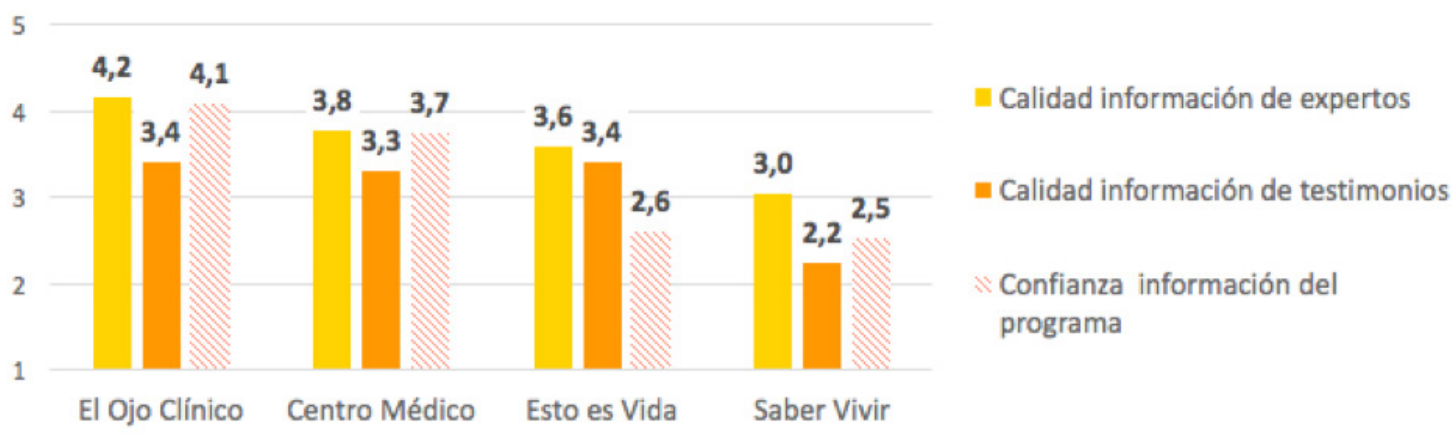

Fuente: elaboración propia.

Gráfico 2. Diagrama de dispersión: correlación entre la edad y el nivel de valoración de la calidad informativa

- los testimonios del público

....... Lineal (los testimonios del público)
- expertos [médicos, científicos]

-. Lineal (expertos [médicos, científicos])

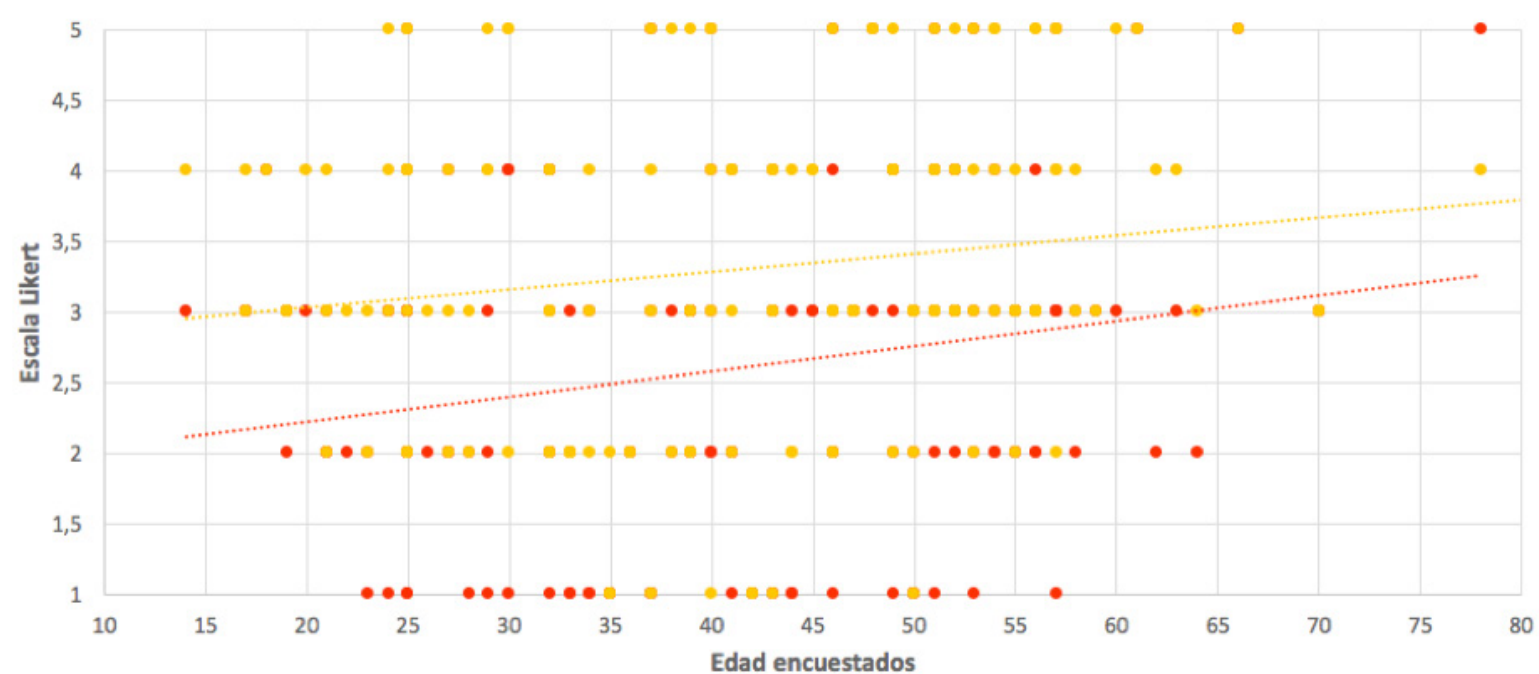

Fuente: elaboración propia.

Gráfico 3. Correlación entre el segmento de edad y el nivel de valoración de la calidad informativa de los expertos y de los testimonios

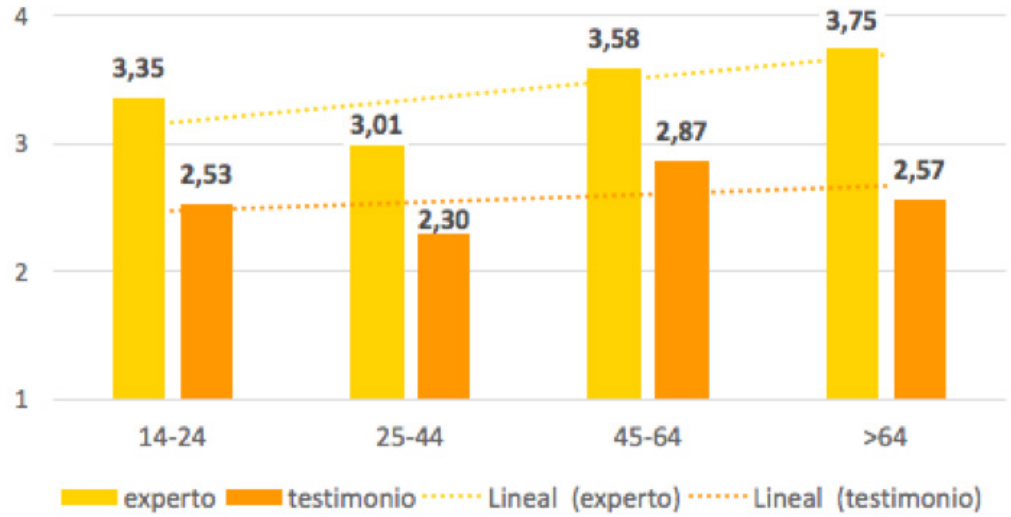

Fuente: elaboración propia. 
Gráfico 4. Distribución por edad de la muestra encuestada

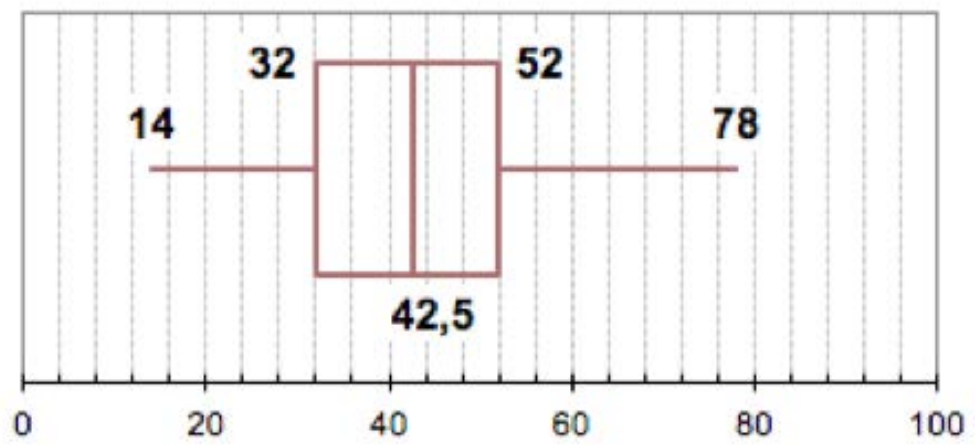

Fuente: elaboración propia.

Gráfico 5. Apreciaciones sobre el lenguaje y las explicaciones de los conceptos científicos

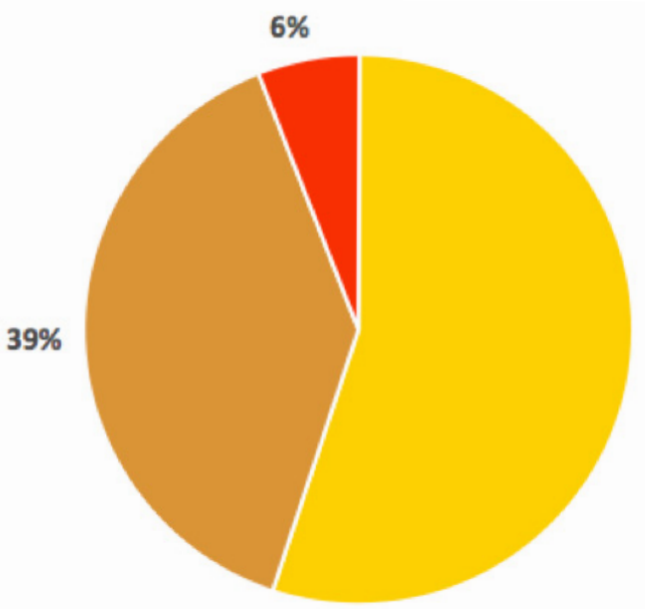
- Entiendo los conceptos científicos,
porque los explican.

- Ninguna de las anteriores.

$55 \%$

Fuente: elaboración propia.

Respecto a los elementos audiovisuales que facilitan la comprensión de las explicaciones científicas, los más valorados por los espectadores son los vídeos externos (29\%) (aquellos grabados fuera del plató), los testimonios, los reportajes en hospitales, etc. Asimismo, también se agradece la adaptación del ritmo del programa a las explicaciones (28\%) y las animaciones creadas para simular lo que se está explicando (22\%). Como se puede ver en el gráfico 6, lo que menos se valora son las anotaciones en pizarra o en pantalla que simulan una explicación escolar.

Ante la pregunta abierta “¿qué consideras que te ayuda a entender mejor la ciencia del programa?", los espectadores encuestados destacan otros elementos complementarios: estudiar o leer bibliografía especí- fica $(18,1 \%)$ y consultar a especialistas $(18,1 \%)$. Como se puede observar en el gráfico 7, que analiza cuantitativamente los recursos para entender los conceptos científicos a los que se hace referencia, un $11,4 \%$ de los encuestados recurren a las búsquedas en portales de internet.

El análisis de las respuestas a las preguntas abiertas “¿por qué ves el programa televisivo?" (respuesta obligatoria) y "¿quieres comentarnos algo más?" (respuesta opcional) se presenta a continuación estructurado por programa y se sistematiza de forma temática, respondiendo al interés y motivación de su visionado, al consumo y a la evaluación de la calidad informativa. Los resultados cuantitativos se indican al final en el gráfico 8 . 
Gráfico 6. Utilidad de los audiovisuales empleados para explicar los conceptos científicos

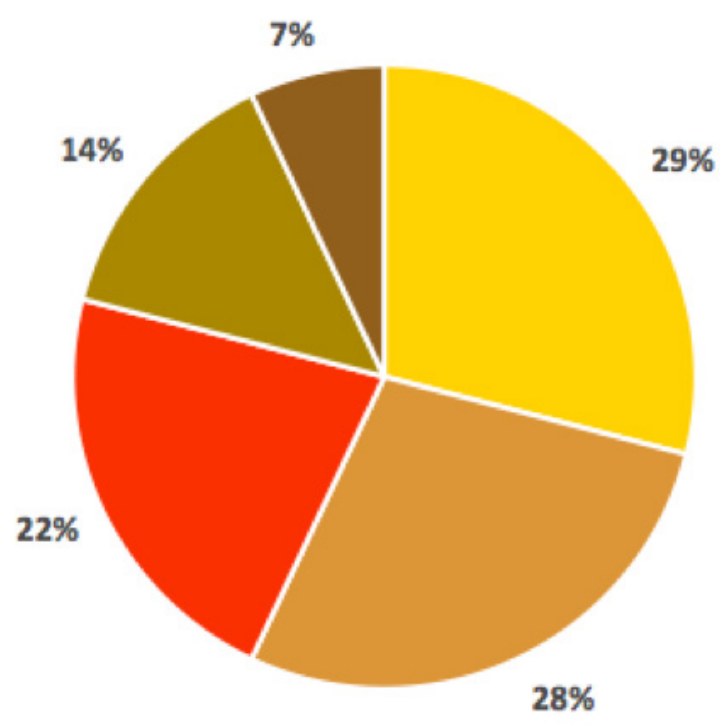

Vídeos externos

- El ritmo se adapta a la explicación

- Animaciones

- Teatralización / Dramatización

- Anotaciones

Fuente: elaboración propia.

Gráfico 7. Frecuencia relativa de las respuestas a la pregunta abierta “¿qué otros elementos te ayudan a entender la ciencia?" ( $n=105)$

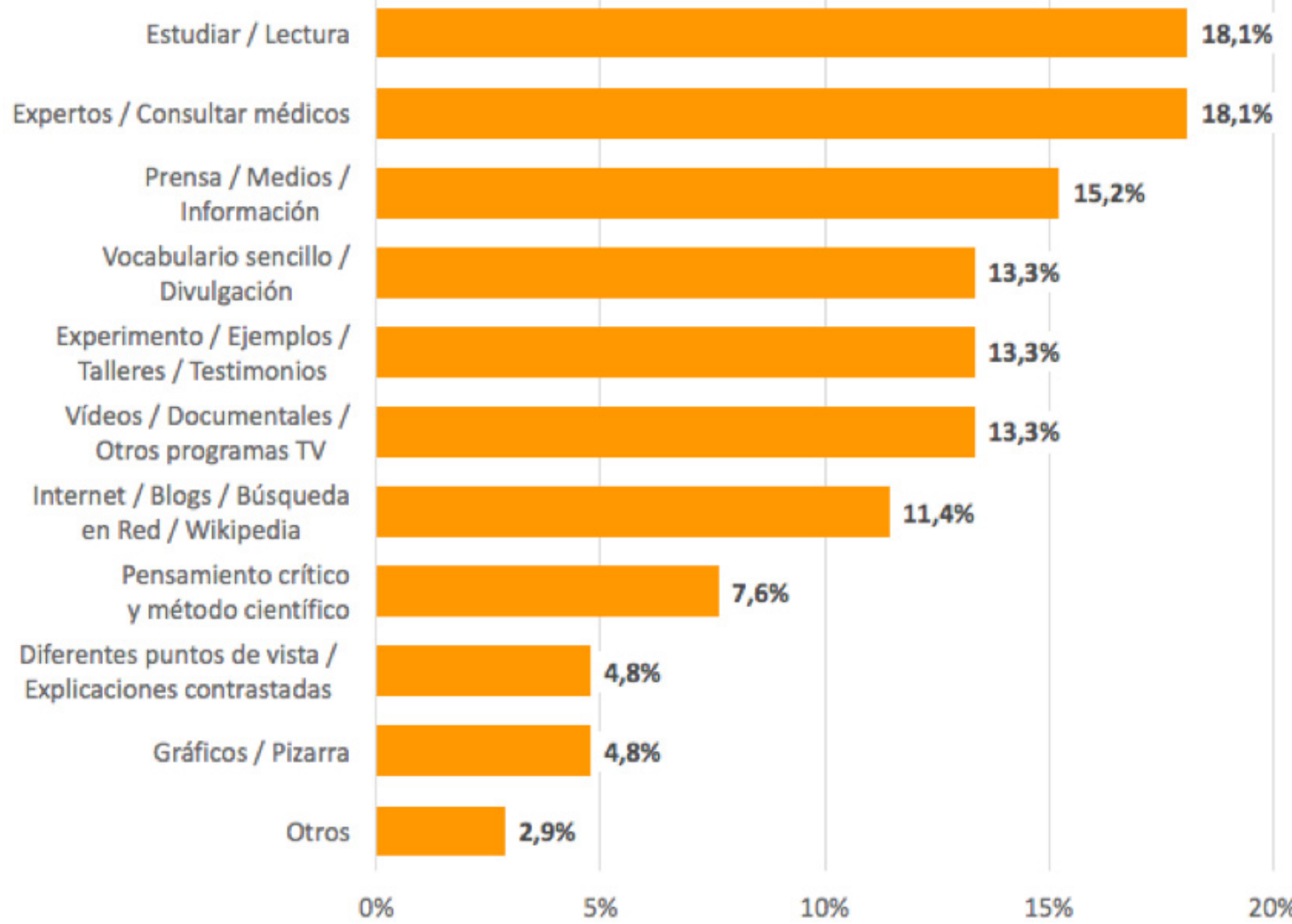

Fuente: elaboración propia. 


\section{Saber vivir}

El interés que motiva principalmente a los espectadores de Saber vivir es la posibilidad de mejorar su salud a través del aprendizaje sobre síntomas, remedios y tratamiento de diversas enfermedades:

"Aunque la información no es muy extensa y clara en muchas ocasiones, para los que no sabemos de medicina... algo se aprende" (mujer, 25 años).

En general desean "conocer un poco más acerca de hábitos saludables" (mujer, 46 años) y ven el programa por la presentación de "remedios caseros, y diversos tratamientos médicos para determinadas enfermedades" (mujer, 25 años), aunque alguno se interesa por los "conceptos científicos y técnicos que podría usar en el futuro" (hombre, 27 años), que aporta Saber vivir.

También se hace referencia a la tercera edad, segmento de edad principal consumidor del programa:

"Da consejos útiles, sobre todo para la gente mayor" (mujer, 20 años).

Entre la audiencia también existe la figura del médico o experto que consume el programa con objetivos analíticos o profesionales:

"Por saber qué explican a la gente, soy enfermera" (mujer, 27 años).

Sin embargo, estos casos son excepcionales: en general existe un interés por la mejora de la salud propia. En las preguntas abiertas este interés queda remarcado a través de los pronombres posesivos:

"Me preocupo por mi bienestar y me gusta aprender cosas nuevas sobre mi salud" (hombre, 40 años).

"[Aprendo] conocimiento sobre aspectos de la salud que me ayudan a mejorar mi salud" (hombre, 52 años).

"Por entretenimiento sano y conocimiento de tu cuerpo" (hombre, 49 años).

"No lo veo a menudo, pero cuando lo veo sus informaciones y consejos me ayudan a cuidar mi salud un poco más" (mujer, 57 años).

Sin embargo, también existe una visión negativa del supuesto aprendizaje:

"No [me aporta nada Saber vivir], porque me gustan los diagnósticos personalizados del médico y no las generalidades" (mujer, 56 años).

"[...] No creo que sea un programa adecuado para aprender ciencia” (mujer, 32 años).
Entre los que afirman estar enfermos, también parece que Saber vivir les ayuda a conocer mejor su enfermedad y los tipos de tratamientos y a reconocer síntomas:

"Te informan de algunas enfermedades y aprendo cómo combatirlas. Por ejemplo, la hipertensión, soy hipertensa" (mujer, 46 años).

"Puedes reconocer un síntoma y saber cómo cuidarte" (mujer, 51 años).

"Hablan de alguna de mis enfermedades" (mujer, 45 años).

En este último caso, es posible que algunos de los espectadores reconozcan ciertos de los síntomas y declaren que ellos los padecen, tal y como lo indican Echegaray Eizaguirre et al. (2014). Como afirma una de las encuestadas:

“Aprendes de la información general, pero a veces con la información continuada parece que tengas todas las enfermedades que plantean en el plató" (mujer, 62 años).

Muchos de los encuestados afirman que no son fieles a la programación diaria, lo ven de forma esporádica, porque "coincidía con [el] rato de descanso [...]" (mujer, 46 años) o con la hora de la comida y siesta. Es un visionado accidental, cuando hacen zapping:

"Solo lo veo un rato cuando hago zapping, tampoco es que aguante demasiado sus tonterías" (mujer, 44 años).

Lo ven "de pasada" (hombre, 29 años) y porque "no hacen nada mejor" (hombre, 38 años).

Consideran que "es preferible este tipo de programas a los de cotilleos" (mujer, 41 años) y que "a veces está puesto por tener algo de fondo y te das cuenta las absurdeces que cuentan" (mujer, 25 años).

También es importante la influencia de la familia en lo que respecta al consumo del programa y la jerarquía entre los miembros a la hora de seleccionar el canal que predomina en el televisor del hogar. Algunos afirman que lo ven porque "lo ve mi abuela" (hombre, 21 años) o "lo ve mi suegra" (mujer, 51 años). En definitiva, consumen a menudo el programa porque "lo ven mis familiares, y es lo que está puesto en la TV" (mujer, 33 años), y no precisamente porque sea de su agrado:

"Lo tiene puesto mi abuela, no lo considero un programa que tenga mucho rigor científico" (mujer, 33 años). 
"No lo veo, solo cuando voy a casa de mis padres. No aporta nada, solo desinformación" (mujer, 43 años). Esta misma informante añade como comentario final:

"Deberían de quitar esos programas, solo sirven para malinformar".

También entre los encuestados existe una minoría que lo ve por mero entretenimiento:

"Lo veo en ocasiones, como Cuarto milenio, como entretenimiento" (hombre, 36 años).

O simplemente: "me hace gracia” (mujer, 33 años).

En cuanto a las menciones directas sobre la calidad informativa de Saber vivir, existen más comentarios negativos que positivos.

Como comentario positivo, un informante destaca que Saber vivir ayuda a esclarecer información transmitida de forma popular:

"Aprendo, y confirma o desmiente viejos tópicos" (hombre, 53 años).

Los informantes destacan un uso de un lenguaje próximo a la audiencia:

"Las explicaciones son claras" (hombre, 53 años).

Se valora positivamente el uso de términos familiares:

"Adecuan los temas a las personas sencillas, pero sin ser criptófricos, o sea lenguaje sencillo: rotura en lugar de trauma..." (hombre, 47 años).

"Son programas útiles para aprender cómo son las enfermedades al margen de los tecnicismos" (hombre, 55 años).

En definitiva, califican Saber vivir como "[...] un programa fácil y ágil" (mujer, 49 años).

Sin embargo, entre los aspectos negativos cabe remarcar dos temas importantes: por una parte, las numerosas menciones sobre desinformación y, por otra parte, la relación de Saber vivir con la pseudociencia.

Con relación a la pseudociencia, los informantes piden que la información presentada esté contrastada científicamente:

"Lo veo muy poco, con la esperanza de que algún día abandonen la pseudociencia y el intrusismo profesional" (mujer, 33 años). Esta misma participante destaca que para entender mejor la ciencia es necesario "que la información aportada esté basada en la evidencia, y no sesgada".
Los encuestados denuncian la falta de rigor científico, que se ve pronunciado a partir de la promoción de pseudociencias:

"Echo en falta mucho más rigor científico, y sobra muchas veces la propaganda a la pseudociencia, como la homeopatía" (hombre, 23 años).

Algunos informantes piden que se actúe ante este tipo de contenidos:

"Me gustaría que se actuara más cuando salen pseudociencias y maguferias en los medios" (hombre, 35 años).

Sobre la desinformación, los encuestados también se manifiestan en tres ejes principales: la descalificación de los trabajadores e invitados al programa, la falta de expertos y rigor científico y finalmente la labor del ente público de TVE.

La audiencia encuestada solicita que Saber vivir cuente con más intervenciones de expertos, a pesar de que el programa cuenta con una cuota media en pantalla de expertos del $41 \%$, siendo el que menos tiene de los tres aquí estudiados (Cano-Orón et al., 2017), tal y como demuestra el análisis de contenido. Esto es vida y Centro médico, con un $67 \%$ en ambos casos, y El ojo clínico, con una cuota media del $66 \%$. En las preguntas abiertas se pueden ver la exigencia por parte de la audiencia de una información sobre salud impartida principalmente por expertos en el tema:

"[Me ayuda a entender la ciencia] que lo explique un experto, no periodistas o presentadores sin cualificación" (mujer, 29 años).

"Debería ser más real y en cada caso hablar gente experta que le dejen decir la verdad: con la salud no se juega" (hombre, 50 años).

En cuanto a la figura del presentador, los encuestados expresan también comentarios negativos:

"El presentador un poco pesado y un sabelotodo" (hombre, 59 años).

Una participante comenta como positivo el cambio de presentadora, con relación al cese de Mariló Montero y la sucesión de María Casado:

"Me gusta mucho más este último formato con presentadora nueva y médico" (mujer, 54 años).

Los encuestados cuestionan en general la profesionalidad de los trabajadores e invitados en plató:

"Porque algunas veces empiezan a hablar y me divierte oír tantas chorradas juntas, la cuna de las pseu- 
dociencias está en los medios" (mujer, 35 años). Esta misma participante añade como comentario general:

\footnotetext{
"Estaría bien que les dieran un toque para que se dejen de hablar de cosas con ninguna base científica que hacen que gente que no sabe del tema ignore a los que están para ayudarles y acaben en manos de homeópatas y sanadores de energías".
}

No es el único que alude a este asunto: incluso la CNMC ha intervenido recientemente, como se ha presentado anteriormente. Entre las personas que han contestado el cuestionario, esta influencia comercial del programa Saber vivir se ve latente en una de las respuestas:

"Sí, he probado algunos medicamentos que promocionan y me han ayudado a mejorar" (mujer, 66 años).

Esta evidencia prueba que un segmento de la población se ve afectado por la publicidad encubierta de la que ha sido acusado el programa y quedan latentes sus efectos. Por lo tanto, algunos contenidos de Saber vivir irían en contra de los principios sobre los que se debería construir la radiotelevisión pública. El programa tiene una "tendencia a planteamientos sensacionalistas con la información. Es más de presentación de enfermedades o problemas de salud que de potenciar una vida saludable" (mujer, 62 años). Otros informantes añaden:

"En la televisión pública ninguno [de los programas de salud] actual tiene un objetivo médico claro" (mujer, 46 años).

"El tema de la salud no se resuelve solo con un programa en la televisión, sino con medios profesionales adecuados" (hombre, 55 años).

"Creo que este tipo de programas confunden a la gente. Si alguien realmente tiene algún problema de salud debería acudir a su médico que es el que realmente está formado para ello" (mujer, 39 años).

“[...] Me parece patético el médico que sale en este tipo de programas, que a los mismos se les denomine ciencia, y sobre todo que el dinero a la televisión pública debería estar destinado a otro tipo de contenidos" (hombre, 21 años).

En este sentido, tal y como destacan Casas Moreno, Maraver López y Aguaded (2016), uno de los espectadores hace referencia a la necesidad de formación para detectar el rigor científico, y de esta forma hace referencia implícitamente al desarrollo del pensamiento crítico a la hora de consumir productos mediáticos. Como afirma el encuestado:
“En Primaria tendría que haber una clase de rigor científico, que los niños aprendan que bajo el título de científico no todo es cierto" (mujer, 46 años).

Entre los espectadores existen solo dos consumidores de Saber vivir que ven el programa para analizarlo, un escritor y una educadora de salud, y critican férreamente la calidad informativa del mismo:

"[Veo el programa] porque la gente que lo ve está desinformada $y$, al saber qué es lo que ven, puedo desmontar falsas creencias (trabajo en educación para la salud)" (mujer, 35 años).

"[Veo el programa] porque habitualmente lanzan mensajes pseudocientíficos y los expongo y analizo para mi blog" (hombre, 40 años).

\section{Centro médico}

Como en el caso de Saber vivir, los espectadores destacan el factor del aprendizaje a través de la serie, que en general se hace de forma natural:

"Sin quererlo, aprendes términos y enfermedades que existen y a veces somos ajenas a ellas" (mujer, 51 años).

"Me fue enganchando. Tiene un buen equilibrio educación, información, entretenimiento" (hombre, 41 años).

"[Lo veo] porque es educativo y se aprende mucho con los casos clínicos, te hace más listo, te relaja y te ayuda a ser mejor persona, me aporta saber un poco más" (mujer, 17 años).

Estas respuestas subrayan la hipótesis sobre el uso de la ficción audiovisual (cine o televisión) como herramienta educativa, sobre la que se ha reflexionado mucho. Destacan también, entre los valores educativos, que se aprenden consejos preventivos, síntomas de enfermedades y tratamientos:

"Trata temas de salud y te explican el porqué de muchos casos. Además te dan consejos sobre cómo prevenir algunas enfermedades" (mujer, 19 años).

"[Me aporta] saber un poco cómo va el funcionamiento de los hospitales y muchas veces dicen los síntomas de alguna enfermedad y es bueno saberlo" (hombre, 14 años).

Algunos de los espectadores, que afirman estar personalmente enfermos, encuentran en el programa una ayuda, pero también algunos de ellos solicitan la ampliación de información. Dos de los encuestados afirman que les ayuda con su enfermedad: 
"Como paciente crónico de algunas enfermedades me ayuda a poder entender mejor las cosas" (mujer, 51 años).

"[Veo Centro médico] porque aprendo mucho y siempre me ha gustado, y más cuando se da algún caso como el mío, de traumatología (mujer, 30 años).

Otros usuarios participantes muestran su interés en que el programa amplíe la información sobre determinadas enfermedades que padecen. Es decir, estamos ante un público con ganas de consumir más contenidos de salud pero sobre temas personalizados:

"[Como comentario adicional, que se] enfoque más en el tema de pacientes celíacos, ya que tenemos muchas carencias en medicamentos y tratamientos médicos" (mujer, 29 años).

"[...] Me gustaría que hicieran más temas sobre espalda y nervios" (mujer, 30 años).

Igual que en el caso de Saber vivir, el consumo del programa en ocasiones es casual:

"Por el horario... me pilla en casa, y por los actores, que lo hacen casos reales" (mujer, 49 años).

Y también a veces familiar: "porque lo ponen mis padres" (mujer, 19 años).

“Empecé a verlo con mi madre porque a ella le encantaba, y al final acabé enganchada. Me gustan mucho los casos que se han puesto, que no son los típicos" (mujer, 32 años).

Como en Saber vivir, existe entre la audiencia un interés científico-médico con relación a la serie:

"Me resulta interesante, y además me gusta adivinar los diagnósticos de cada caso (soy médico)" (mujer, 25 años).

"Me gusta porque yo trabajo en un hospital" (mujer, 43 años).

Además, que se utiliza para complementar, como anteriormente se ha tratado, por el potencial educativo de esta ficción televisiva:

"Me lo recomendó mi tutora -es médico-. Y dice que se acerca mucho a la realidad, y nos vamos familiarizado con el lenguaje técnico de medicina" (mujer, 18 años).

En cuanto al tratamiento informativo, destaca la percepción de realidad que la serie transmite a los espectadores. En la afirmación anterior, una maestra la recomienda a sus alumnas auxiliares de enfermería, precisamente porque se aproxima a los casos reales del día a día. Por lo tanto, la ficción se acerca a la realidad a la hora de exponer las enfermedades, diagnósticos y tratamientos de las mismas:

"Explican fenomenal todos los casos clínicos, es una serie muy real” (mujer, 48 años).

"Me da confianza, es muy real, y dan las soluciones con cariño y delicadeza” (mujer, 52 años).

Otro de los componentes que los encuestados destacan es la dramatización de esta docuficción: "lo veo de forma puntual, por las tramas" (mujer, 34 años).

Entre las afirmaciones citadas anteriormente, dos de ellas subrayan que la serie "les ha enganchado", posiblemente debido a la continuidad de historias paralelas y personajes, así como a la dramatización del contenido:

"Me fue enganchado [...]" (hombre, 41 años)

"[...] Al final acabé enganchada [...]" (mujer, 32 años).

\section{El ojo clínico}

Igual que en el caso de los otros programas estudiados, la audiencia destaca en unos casos de forma positiva y en otros negativa la adquisición de conocimiento y el aprendizaje a través del programa:

“Me encantó que el primer programa abordara el tema de la depresión. Me pareció audaz, y un programa excelente. Me encanta saber sobre temas médicos" (mujer, 39 años).

"Aprendo y ayuda a la gente" (mujer, 37 años).

En contraposición, otros aluden a la parte negativa:

"Porque me gusta atender a profesionales y no a charlatanes" (hombre, 25 años).

Otro de los espectadores tiene el interés de contrastar la información de la divulgación con su propio conocimiento:

"[Lo veo para] contrastar mis conocimientos con la divulgación científica” (hombre, 39 años).

Un número de encuestados consumen el programa por pertenecer al cuerpo médico o ser profesionales del campo de la sanidad:

"[Lo veo porque] soy estudiante de tercero de enfermería" (mujer, 24 años).

"Soy médico ipero también telespectadora!" (mujer, 57 años). $Y$ añade: 
"Me gusta el primer nivel de atención sanitaria y me identifico perfectamente [con El ojo clínico] porque es el medio en el que trabajo".

"Soy psicóloga y tratan temas que me interesan. Lo hacen sencillo y fácil para no expertos también" (mujer, 30 años).

En cuanto a la percepción de la calidad informativa a través de las preguntas abiertas, la mayoría critica el tratamiento informativo:

"A veces el presentador hace preguntas absurdas a los doctores. El actor hipocondríaco del final para mí sobra. En general me encanta el programa [...]" (mujer, 39 años).

Según otra opinión:

"Sería interesante que los medios de comunicación ofrecieran una visión más holística de la ciencia y no tan fragmentaria y reduccionista" (hombre, 39 años). Este mismo espectador también considera que "la ciencia se entiende y tiene sentido cuando se contrasta con las humanidades y con las terapias naturales".

\section{Esto es vida}

Sobre Esto es vida tan solo tenemos una aportación que se puede destacar:
"[Lo veo], porque es un programa entretenido que cuenta de forma agradable los temas de salud que preocupan a las personas" (hombre, 25 años).

\section{DISCUSIÓN Y CONCLUSIONES}

En 2016 TVE apostó fuertemente por los programas de salud, cumpliendo con su labor de servicio público, ofreciendo productos de entretenimiento, divulgación y educación. Los programas especializados en salud de TVE emitidos en 2016 son cuatro: Saber vivir, Centro médico, Esto es vida y El ojo clínico, de los cuales solo han coincidido en parrilla tres, pues Esto es vida cesó sus emisiones unos días antes de que comenzase El ojo clínico. De estos cuatro, el programa que reúne una mayor audiencia es Centro médico (cifras de rating), la docuficción que está incorporando de forma paulatina más parte de ficción que de divulgación en sus guiones. No obstante, atendiendo a las cifras de share, es decir, en función de la audiencia que hay por franja horaria, es Saber vivir el que más público atrae.

En general estos programas mantienen el mismo tipo de audiencia: mayores de 45 años, sin una gran distinción entre sexos, pues aunque sí existe una ligera mayoría de público femenino, que excede incluso la cuota media de mujeres de la cadena, no es lo suficientemente significativa como para perfilar un sesgo

Gráfico 8. Frecuencia relativa de las respuestas a la pregunta abierta “¿por qué ves el programa?” (n=158)

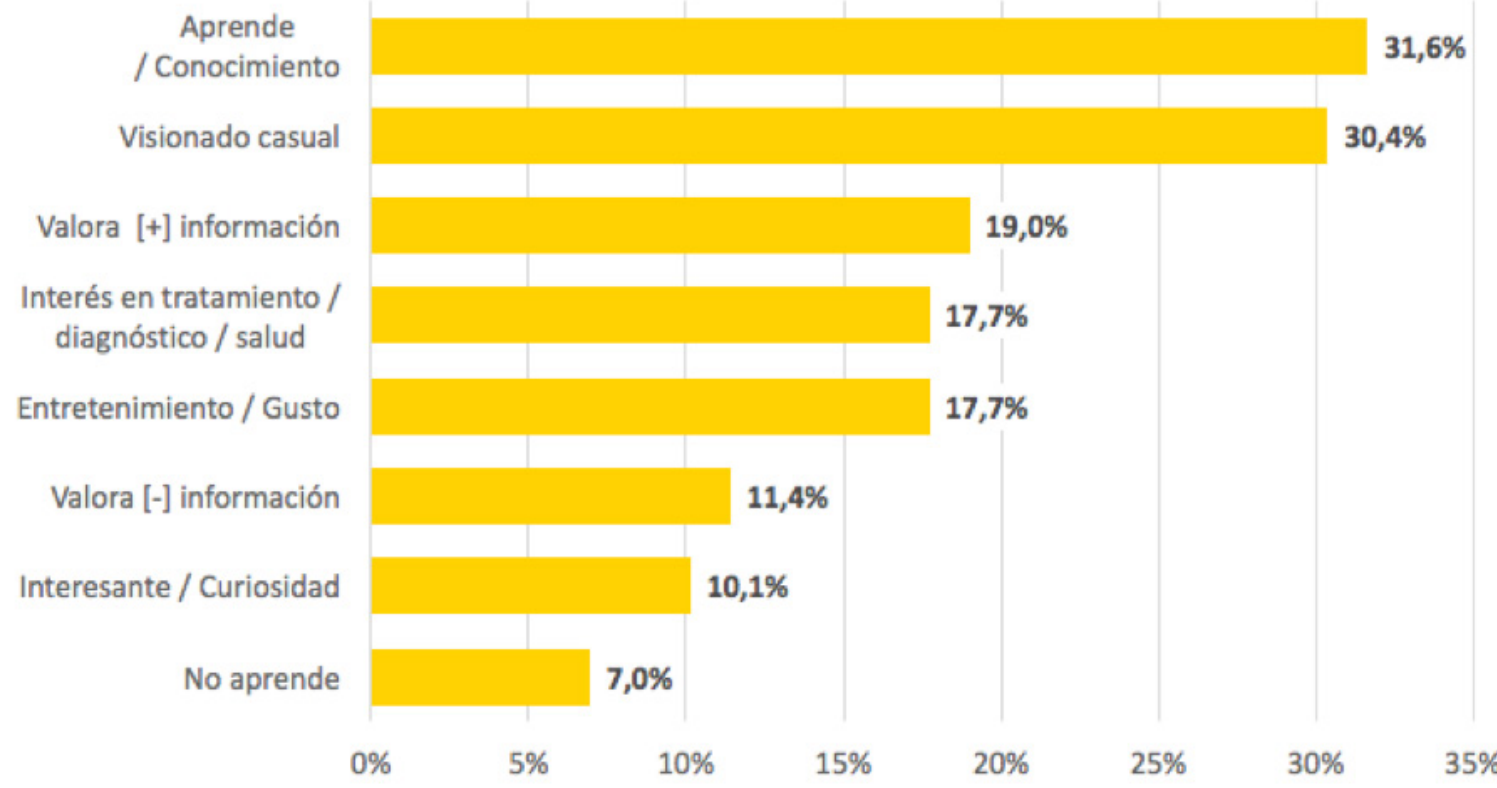

Fuente: elaboración propia. 
de sexo en los programas: un tipo de público bastante esperable tanto por las franjas horarias en las que se emiten como por el tipo de formato televisivo.

Los espectadores encuestados presentan una confianza neutral en los contenidos, una media de 2.92 sobre 5 . No presentan una polarización a favor o en contra de la información que ofrecen los programas. No obstante, sí que se aprecia una confianza positiva hacia los expertos (3,31 sobre 5) y, por el contrario, una desconfianza en la información presentada mediante testimonios (2,61 sobre 5). Es decir, los informantes valoran positivamente la intervención de médicos y de expertos científicos, por encima de los testimonios en primera persona del público participante. De hecho, más de la mitad de los encuestados valora positivamente las explicaciones de los conceptos científicos que se desarrollan en los programas. De entre los cuatro programas estudiados, El ojo clínico es el mejor valorado por la calidad de sus contenidos, mientras que Saber vivir es el que peores valoraciones recibe.

Existe una débil correlación entre la confianza en la información y la edad. La población joven (25-44 años) es el segmento que más desconfía en la información que exponen estos programas. Sin embargo, para una futura investigación sería interesante tener en cuenta el nivel de estudios y poder analizar una muestra más representativa de espectadores.

En cuanto a las respuestas a preguntas abiertas, en general existe una opinión positiva respecto a la programación, y los informantes destacan el aprendizaje y la divulgación de información. La motivación de los espectadores es mejorar su propia salud. Sin embargo, surgen reproches en cuanto al tratamiento informativo en algunos de los programas, como en el caso de Saber vivir, con fuertes acusaciones de desinformación, de promoción de las pseudociencias y de participación sesgada de profesionales. El ojo clínico también es criticado por algunas de las figuras profesio- nales que participan en plató. En contraposición, no existen comentarios negativos de Centro médico, cuya particularidad es la percepción de realidad por parte de la audiencia, que incluso algunos de los encuestados confiesan recomendar en clase para aproximarse a los casos reales, aun tratándose de una docuficción.

Los espectadores piden, en general, más rigor, ampliación de la información y más programación sobre sanidad en la televisión pública. La audiencia se perfila de algún modo como el nuevo tipo de paciente presentado por Echegaray Eizaguirre et al. (2014), que busca estar informado y tomar un papel activo en su salud. Sin embargo, esto no equivale a que la ciudadanía no sea crítica con la información que consume (véase el gráfico 2), o que sepa discernir información veraz de noticias falsas, así como descodificar la información audiovisual que recibe. Por lo tanto, es fundamental fomentar la alfabetización mediática en los espectadores, así como el interés ante la ciencia y la tecnología.

En futuras investigaciones se intentará eliminar una de las principales limitaciones de este estudio, que ha sido llegar solo a la audiencia que está activa en redes sociales. Ampliar la horquilla de participantes haciendo encuestas físicas y acudiendo a una determinada franja de edad que cumple con el perfil de la cadena sería lo aconsejable para profundizar en el estudio.

\section{AGRADECIMIENTOS}

El presente trabajo ha sido desarrollado en el marco del proyecto de investigación Estudio y clasificación de las terapias naturales, complementarias y alternativas a través de los medios de comunicación y de las redes sociales. Ideas y valores de transferencia al imaginario social (CSO2014-57778-R), financiado por el Ministerio de Economía y Competitividad y por fondos FEDER de la Unión Europea. Las autoras desean agradecer a la profesora Carolina Moreno Castro sus comentarios, que ayudaron a mejorar el manuscrito.

\section{NOTAS}

[1] Este programa se emitió desde el 13 de marzo de 1976 al 18 de octubre de 1978 (véase Finaliza el programa de TVE "Escuela de salud"). Era presentado y dirigido por Manuel Torreiglesias y consiguió posicionarse como uno de los programas con mayor audiencia (Pérez Ornia, 1978, 19 septiembre).
[2] Manuel Torreiglesias continuó en las siguientes temporadas presentándolo en solitario hasta mayo de 2009 , cuando fue despedido por incumplir las normas de publicidad y fue sustituido por el doctor Luis Gutiérrez, que se mantuvo como presentador del programa y de la sección La mañana hasta 2013. EI doctor Julio Zarco presentó esa sección en esa temporada, momento en el que comenzaría a tomar protagonismo Ana Bellón, actual directora de la sección. 


\section{BIBLIOGRAFÍA}

Aldoory, L. (2017). The Status of Health Literacy Research in Health Communication and Opportunities for Future Scholarship. Health Communication, 32 (2), pp. 211-218. https://doi.org/10.1080/1 0410236.2015.1114065

Asbeek Brusse, E. D., Fransen, M. L. y Smit, E. G. (2015). Educational storylines in entertainment television: audience reactions toward persuasive strategies in medical dramas. Journal of Health Communication, 20 (4), pp. 396-405. https://doi.org /10.1080/10810730.2014.965365

Cano-Orón, L., Portalés Oliva, M. y LlorcaAbad, G. (2017). La divulgación de salud en la televisión pública: el caso de RTVE en 2016. AdComunica, 14, pp. 201-228.

Casas Moreno, P. de, Maraver López, P. y Aguaded, I. (2016). Análisis de contenido de la programación sensacionalista pública española: propuesta de cuestionario como medidor de los hábitos de la audiencia audiovisual. Icono14, 14 (1), pp. 1-23. https://doi.org/10.7195/ri14. v14i1.914

Domínguez Lázaro, M. R. (2015). Tratamiento, lenguaje y técnicas de comunicación efectivas para educar en salud a través de discursos audiovisuales. En Pozo Cruz, J. T. del, Román San Miguel, A. Alcántara López, R. y Domínguez Lázaro, M. R. (coords.). Medios de comunicación y salud. Sevilla: Astigi, pp. 59-70.

Echegaray Eizaguirre, L., Peñafiel Saiz, C. y Aiestaran Yarza, A. (2014): Análisis de la percepción de los profesionales de la medicina sobre la información en salud en la prensa vasca y navarra. Estudios sobre el Mensaje Periodístico, 20 (1), pp. 341-357. https://doi.org/10.5209/ rev_ESMP.2014.v20.n1.45236

Francescutti, P. (2012). Epidemiología televisiva: las patologías de los españoles según los informativos. En: Semir, V. de y Revuelta, G. (coords.). El periodismo biomédico en la era 2.0. Barcelona: Fundación Dr. Antonio Esteve, pp. 31-38. Disponible en https://www.esteve.org/ capitulos/documento-completo-25/

Lazo, C. M. y Grandío, M. M. (2013). Análisis de la competencia audiovisual de la ciudadanía española en la diimensión de recepción y audiencia. Communication \& Society / Comunicación y Sociedad, 26 (2), pp. 114-130.

Lehmkuhl, M. (2014). Current state and challenges of science in today's TV: a look at the interplay between supply and demand in European media markets. Actes d'Història de la Ciència i de la Tècnica, 7, pp. 89-112.

León, B. (2002). Divulgar la ciencia en televisión: problemas y oportunidades. En Façeira, M. J. (ed.). A divulgação científica nos medios. Avanca: Cine-clube Avanca, pp. 73-79.

Lobera, J. (ed.) (2017). Percepción social de la ciencia y la tecnología 2016. FECYT. Fundación española para la ciencia y la tecnología. [En línea]. Disponible en https://www.fecyt.es/es/publicacion/ percepcion-social-de-la-ciencia-y-la-tecnologia-en-espana-2016

López Villafranca, P. (2015). La representación de la Asociación de pacientes en el ente público de RTVE. El caso de las enfermedades raras. En Peñafiel, C. y Terrón, J. L. (coords.). Estudios de comunicación y salud: innovaciones $e$ información científica para el progreso social. La Laguna: Sociedad Latina de Comunicación Social, pp. 158-175.

Moreno Castro, C. (2004). Evolución y tendencias de los formatos televisivos de divulgación científica en España. Quaderns de Filologia. Estudis de Comunicació, 2, pp. 121-136.

Moreno Castro, C. (2009). Los medios, el público y la ciencia. Una relación que no progresa adecuadamente. En Fundación Española para la Ciencia y la Tecnología (FECYT). Percepción Social de la Ciencia y la Tecnología en España 2008. FECYT. Fundación Española para la Ciencia y la Tecnología, pp. 21-37. [En línea]. Disponible en https://www.fecyt.es/es/publicacion/percepcion-social-de-la-cienciay-la-tecnologia-en-espana-2008

Moyer-Gusé, E. y Nabi, R. L. (2011). Comparing the Effects of Entertainment and Educational Television Programming on Risky Sexual Behavior. Health Communication, 26 (5), pp. 416-426. https://doi. org/10.1080/10410236.2011.552481

Peñafiel, C., Ronco, M., y Echegaray, L. (2016). ¿Cómo se comportan los jóvenes y adolescentes ante la información de salud en Internet? Revista Española de Comunicación en Salud, 7(2), pp. 167-189.

Quintero Johnson, J. M., Harrison, K. y Quick, B. L. (2013). Understanding the effectiveness of the entertainmenteducation strategy: An investigation of how audience involvement, message processing, and message design influence health information recall. Journal of Health Communication, 18 (2), pp. 160-178. https://doi.org/10.1080/1081 0730.2012 .688244

Sánchez Martos, J. (2010). La información sobre la salud en los medios de Comunicación. Revista Española de Comunicación en Salud, 1 (2), pp. 68-76.

Semir, V. de y Revuelta, G. (2006). La salud en el supermercado de la información. Humanitas, Humanidades Médicas, 4, pp. 11-23.

Sharf, B. F. y Freimuth, V. S. (1993). The construction of illness on entertainment television: Coping with cancer on thirtysomething. Health Communication, 5 (3), pp. 141-160. https://doi. org/10.1207/s15327027hc0503_1

Terrón Blanco, J. L. (2007). La comunicación para la salud en España, algunos apuntes. Eco-Pos, 10 (1), pp. 23-44.

Torres Albero, C. (ed.) (2015). Percepción social de la ciencia y la tecnología 2014. FECYT. Fundación Española para la Ciencia y la Tecnología. [En línea]. Disponible en https://www.fecyt.es/es/publicacion/percepcion-social-de-la-ciencia-yla-tecnologia-2014

Yoo, J. H. y Tian, Y. (2011). Effects of Entertainment (Mis) Education: Exposure to Entertainment Television Programs and Organ Donation Intention. Health Communication, 26 (2), pp. 147-158. https://doi.org/ 10.1080/10410236.2010.542572

\section{Otros recursos}

Álvarez, I. (2015, 26 octubre). La 1 se vuelca con la salud y llena su parrilla con espacios sobre medicina. $20 \mathrm{mi}$ nutos [En línea]. Disponible en: http:// www.20minutos.es/noticia/2588660/0/ la-1-programas-salud/medicina-centromedico/esto-es-vida/

CIS. Centro de Investigaciones Sociológicas. Barómetro sanitario 2015 (tercera oleada). Estudio n. 3115. Octubre 2015. [En línea]. Disponible en: http://www.cis.es/ cis/export/sites/default/-Archivos/Marginales/3100_3119/3115/es3115mar.pdf

CIS. Centro de Investigaciones Sociológicas. Barómetro de noviembre 2016. Avance de resultados. Estudio n. 3159. Noviembre 2016. [En línea]. Disponible en: http://datos.cis.es/pdf/Es3159mar_A. pdf 
Comunicado del espacio de TVE 'Saber Vivir'. RTVE Sala de comunicación, 18 febrero 2015. [En línea] Disponible en: http://www.rtve.es/rtve/20150218/ comunicado-del-espacio-tve-saber-vivir/1100601.shtml

Finaliza el programa de TVE "Escuela de salud". El País, 18 octubre 1978. [En línea]. Disponible en http://elpais.com/diario/1978/10/18/sociedad/277513222_850215.html

Gallo, I. (2009, 8 mayo). TVE despide a Manuel Torreiglesias. El País. [En línea]. Disponible en: http:// elpais.com/diario/2009/05/08/radiotv/1241733602_850215.html

Gámez, L. A. (2015, 3 enero). TVE promociona la homeopatía contra los catarros y la gripe. Magonia. Una ventana crítica al mundo del misterio. [En línea]. Disponible en: http://magonia. com/2015/01/03/tve-promociona-lahomeopatia-contra-catarros-y-gripe/

La nueva apuesta de Salud para las tardes de TVE provoca un intenso debate entre directivos. El Confidencial digital, 23 octubre 2015. [En línea].
Disponible en: https://www.elconfidencialdigital.com/articulo/medios/ Salud-TVE-provoca-intenso-directivos/20151022185637079026.html

Martínez, I. (2015, 3 enero). Saber Vivir ¿servicio público? [En línea]. Disponible en: http://quemalpuedehacer.es/ blog/2015/01/03/saber-vivir-serviciopublico/

OMC. Organización Médica Colegial de España. Consejo General de Colegios Oficiales de Médicos. Carta al Defensor del Espectador de TVE: La OMC envía una queja por las declaraciones de Mariló Montero. 12 febrero 2015. [En línea]. Disponible en http://www.cgcom.es/noticias/2015/12/15_02_12_tve

Pérez Mendoza, S. (2016, 11 octubre). Competencia multa con 150.000 euros a TVE por publicidad encubierta en 'La mañana de La 1'. Eldiario.es. [En línea]. Disponible en http://www.eldiario.es/ sociedad/Competencia-TVE-publicidadencubierta-manana_0_568343549.html

Pérez Ornia, J. R. (1978, 19 septiembre). Desaparece el programa de televisión "Escuela de salud". El País.
[En línea]. Disponible en: http://elpais.com/diario/1978/09/19/sociedad/275004008_850215.html

Rating es 'índice de audiencia' y share, 'cuota de pantalla'. Fundéu, 22 noviembre 2011. [En línea]. Disponible en http:// www.fundeu.es/recomendacion/ratinges-indice-de-audiencia-y-share-cuotade-pantalla-1043/

Saber Vivir. 2000 días a tu lado. TVE Saber Vivir. Informa 2007. [En línea]. Disponible en: http://www.rtve.es/files/1013924 -FICHERO/SaberVivirDossier. pdf?download $=1$

Salud y bienestar en las tardes de TVE. Europapress, 26 octubre 2015. [En línea]. Disponible en: http://www.europapress. es/chance/tv/noticia-salud-bienestartardes-tve-20151026155143.html

Sevillano, E. G. (2015, 23 abril). Los consejos de salud de Mariló Montero, a debate en el Congreso. El País. [En línea]. Disponible en: https://elpais. com/politica/2015/04/23/actualidad/1429784417_080308.html 